\title{
Autumn atmospheric response to the 2007 low Arctic sea ice extent in coupled ocean-atmosphere hindcasts
}

\author{
Yvan J. Orsolini • Retish Senan • Rasmus E. Benestad • \\ Arne Melsom
}

Received: 9 February 2011/Accepted: 12 August 2011/Published online: 24 August 2011

(C) The Author(s) 2011. This article is published with open access at Springerlink.com

\begin{abstract}
The autumn and early winter atmospheric response to the record-low Arctic sea ice extent at the end of summer 2007 is examined in ensemble hindcasts with prescribed sea ice extent, made with the European Centre for Medium-Range Weather Forecasts state-of-the-art coupled ocean-atmosphere seasonal forecast model. Robust, warm anomalies over the Pacific and Siberian sectors of the Arctic, as high as $10^{\circ} \mathrm{C}$ at the surface, are found in October and November. A regime change occurs by December, characterized by weaker temperatures anomalies extending through the troposphere. Geopotential anomalies extend from the surface up to the stratosphere, associated to deeper Aleutian and Icelandic Lows. While the upper-level jet is weakened and shifted southward over the continents, it is intensified over both oceanic sectors, especially over the Pacific Ocean. On the American and Eurasian continents, intensified surface Highs are associated with anomalous advection of cold (warm) polar air on their eastern (western) sides, bringing cooler temperatures along the Pacific coast of Asia and Northeastern North America. Transient eddy activity is reduced over Eurasia, intensified over the entrance and exit regions of the Pacific and Atlantic storm tracks, in broad qualitative agreement with the upper-level wind anomalies. Potential predictability calculations indicate a strong influence of sea ice upon surface temperatures over the Arctic in autumn, but also along the Pacific coast of Asia in December. When the
\end{abstract}

Y. J. Orsolini $(\bowtie)$

Norwegian Institute for Air Research (NILU), PO BOX 100, 2027 Kjeller, Norway

e-mail: yvan.orsolini@nilu.no

R. Senan · R. E. Benestad · A. Melsom

Norwegian Meteorological Institute (met. no), Oslo, Norway observed sea ice extent from 2007 is prescribed throughout the autumn, a higher correlation of surface temperatures with meteorological re-analyses is found at high latitudes from October until mid-November. This further emphasises the relevance of sea ice for seasonal forecasting in the Arctic region, in the autumn.

Keywords Sea ice - Atmospheric modeling - Cryosphere · Seasonal forecasting $\cdot$ Predictability

\section{Introduction}

The Arctic sea ice extent has rapidly been decreasing in all seasons since monitored from space in the late seventies, and the highest negative trend is observed in late summer (Serreze et al. 2007; Stroeve et al. 2007). Superposed on this negative trend, there is considerable inter-annual variability and marked reductions were observed in recent years: the lowest extent was observed in summer 2007, when sea ice disappeared over large portions of the Pacific and Siberian sectors of the Arctic, the second lowest in 2008, and the third lowest in 2010. The summertime interannual variability falls under the influence of complex driving factors, such as the high-latitude atmospheric circulation patterns, the inflow of warm Pacific or Atlantic waters into the Arctic Ocean, the preconditioning by low sea ice thickness in late winter, as well as the cloudiness that strongly affects the radiative budget (Zhang et al. 2008a, b; Wang et al. 2009; Ogi et al. 2010; Ogi and Yamazaki 2010; Overland and Wang 2010). Several of these factors have been suggested to contribute to the record low extent of 2007. The persistent surface dipole anomaly over the Arctic in that summer in particular, has been instrumental in bringing moist Pacific air into the 
Arctic and driving sea-ice export through the Fram Strait (Inoue and Kikuchi 2007). In summers with reduced sea ice extent, the lowered albedo over ice-free areas allows warming of the surface waters, and the upper ocean hence stores heat (e.g. Steele et al. 2010). Re-analysis data show that, in the following autumns, a large surface heat flux from the open waters to the cooling atmosphere above leads to an anomalous warming of the lower Arctic atmosphere (Serreze et al. 2009; Kumar et al. 2010; Overland and Wang 2010; Screen and Simmonds 2010).

Several climate model studies investigated the atmospheric response to winter (Alexander et al. 2004; Deser et al. 2004, 2010; Johannessen et al. 2004; Seierstad and Bader 2009; Petouhkov and Semenov 2010) or summer (Bhatt 2008; Benestad et al. 2011) sea ice anomalies. The impact of low sea ice anomalies in late summer or autumn on the large-scale circulation and weather patterns in the following months has been, however, little explored. Francis et al. (2009) examined National Center for Environmental Prediction (NCEP) re-analyses over the years 1976-2006. They found lasting anomalies in the 6 months following low summer sea ice conditions: a weakening of the Aleutian and Icelandic Lows, reduced mid-latitude jet streams, as well as a surface warming over the Arctic and cooling over Central Asia. Cold early winter temperature anomalies over the Far East were also found by Honda et al. (2009) in meteorological analyses in 2005 and 2008, both summers with low Arctic sea ice, as well as in atmospheric model simulations with prescribed, reduced sea ice extent in the Siberian sector of the Arctic. They also investigated the late winter response, and found negative temperature anomalies in a zonally elongated band stretching from Europe across Eurasia. The mechanisms that would link low Arctic sea ice extent in late summer with cold autumn and winter anomalies across Eurasia are not fully understood. Other atmospheric forcings, such as the strong La Nina in 2007/2008, may obscure the statistical analysis of meteorological data. A recently published multi-model study with atmosphere-only models by Kumar et al. (2010) investigated the seasonality and vertical structure of the temperature response to the observed sea ice extent of 2007. In agreement with Benestad et al. (2011), they found little summertime influence, but in autumn however, they found a large, low-level surface warming in agreement with observations. Autumn surface anomalies are important for winter climate, as indicated by recent studies on the influence of the autumn Eurasian snow cover extent on the wintertime circulation (Cohen et al. 2007; Orsolini and Kvamstø 2009).

The respective roles of regional sea ice reductions in the Pacific, Siberian or Barents Sea sectors of the Arctic are not fully understood. Previous global model studies (cited above) on the atmospheric response to Arctic sea ice anomalies were made at low or moderate resolution. Regional Arctic-wide models (e.g. Rinke et al. 2006; Strey et al. 2010) can better address the effect of localised sea ice anomalies, but, being forced at lateral boundaries by analysed meteorological fields, cannot reveal global linkages. Further dedicated, high-resolution model experiments seem necessary to address these combined issues.

In this study, we analyse the autumn and early-winter (October to December) response to the record low sea ice extent of late summer 2007, using the high-resolution coupled ocean-atmosphere seasonal forecast model of the European Centre for Medium-Range Weather Forecasts (ECMWF) with prescribed sea ice extent. An ensemble approach coupled to a potential predictability analysis is carried out to identify regions responsive to sea ice extent variability. While several recent studies have also addressed the atmospheric impact of the 2007 sea ice reduction, our study uniquely uses a higher resolution model as well allowing a two-way coupling between the atmosphere and ocean. It is also a forecast model with realistic initialization and prescribed sea ice. Summertime (May-September) simulations for 2007 or 2008 with the same model have been analysed in Balmaseda et al. (2010) and Benestad et al. (2011). We focus here on new autumn and earlywinter simulations, which we refer to as hindcasts and not forecasts, due to the fact that sea ice is prescribed.

\section{Method}

Five-month hindcasts starting on October 1, 2007 were performed with the ECMWF coupled atmosphere-ocean model (IFS/HOPE System 3) (e.g. Balmaseda et al. 2010 and references therein), using the cycle $31 \mathrm{r} 1$ of the IFS atmospheric model with a spatial resolution of T159 and 62 vertical levels extending up to $5 \mathrm{hPa}$. The ensemble simulations were initialized with operational atmospheric and ocean analyses (Balmaseda et al. 2008), and comprise five members generated from perturbations in sea surface temperature (SSTs) applied as initial conditions and tapered during the first month.

There is no dynamical sea ice model in the current ECMWF operational seasonal forecast model. The constant-thickness sea ice is initialized based on SSTs from the ocean analyses. Sea ice is present when SSTs are below freezing point $\left(\approx-1.7^{\circ} \mathrm{C}\right)$. The initial sea ice extent persists in the forecast for 10 days, and is subsequently relaxed rapidly toward a climatological seasonal cycle derived from ERA-40 re-analyses. Following Balmaseda et al. (2010) and Benestad et al. (2011), the operational model was adapted to prescribe the sea ice extent derived from ocean analyses, throughout the 5-month simulation in both hemispheres. In order to test the sensitivity of the atmospheric response, we ran five additional ensembles 
with "erroneous" sea ice extent prescribed from the five preceding years (2002-2006).

In summary, we performed six 5-member ensembles of hindcasts for the period October 2007 to February 2008, providing a "super-ensemble" of 30 hindcasts. We identify anomalous atmospheric responses by contrasting the mean of the 5-member ensemble using the actual 2007 sea ice extent, to the super-ensemble mean. In the following, we will refer to this difference as the 2007 anomaly. By looking at this anomaly field, we do not address potential model bias. It is important to note that all hindcasts are for the same autumn and early winter period of 2007/2008, and only the sea ice extent is from other years. We focus on the period October to December, when the responses are more robust.

Figure 1 shows the October-to-February evolution of the prescribed sea ice extent north of $60^{\circ} \mathrm{N}$ for all the years used. In early October 2007, the sea ice extent is lower by 1.5 $10^{6} \mathrm{~km}^{2}$ compared to other years, and the negative anomaly persists until late November. The model 2007 anomaly in surface sensible heat flux for October is also shown (inset) in Fig. 1. Negative anomalies, as high as $60 \mathrm{~W} \mathrm{~m}^{-2}$ over the Pacific and Siberian sectors of the Arctic, indicate ocean loosing heat to the atmosphere. Smaller, localized positive heat flux anomalies can also be found, and might result from advection of warm air over the ocean.

\section{Modelled 2007 anomalies in temperature, sea level pressure and upper-level wind}

The 2007 monthly temperature anomalies are shown in Fig. 2 at $80^{\circ} \mathrm{N}$ as longitude-pressure cross sections, from

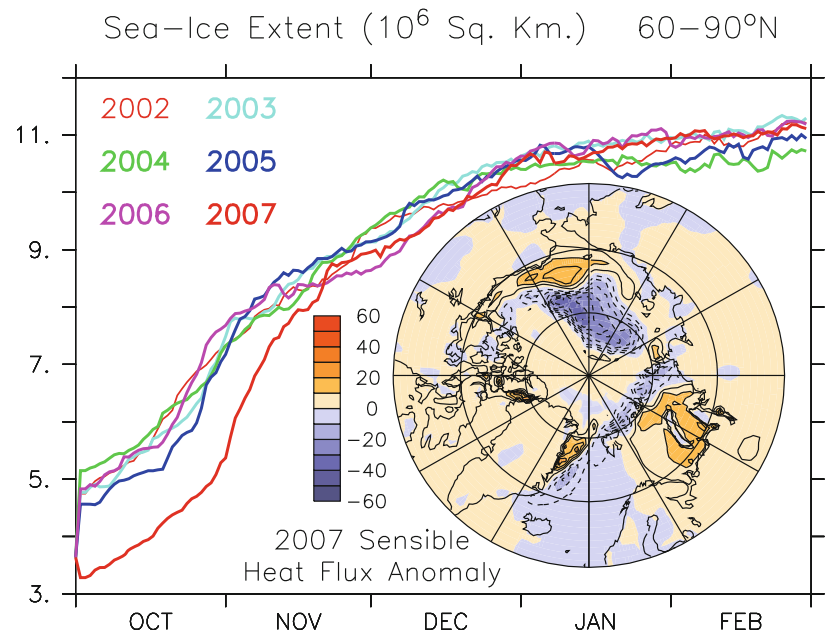

Fig. 1 Seasonal evolution of sea ice extent (where sea ice concentration is higher than $15 \%$ ) from 2002 to 2007 prescribed in the different experiments. The model 2007 anomaly (see text for definition) in the surface sensible heat flux during October is shown in the inset. Negative values indicate ocean loosing heat to the atmosphere. Units are $\mathrm{W} \mathrm{m}^{-2}$
October to December. A low level warm anomaly, as high as $10^{\circ} \mathrm{C}$ in October and November, extends from a surface maximum up to about $800 \mathrm{hPa}$. The warm anomaly magnitude is consistent with the findings of Serreze et al. (2009) based on the NCEP anomalies from the 1979-2007 period. The 2007 anomalies in two-meter temperature $\left(\mathrm{T}_{2 \mathrm{~m}}\right)$ are shown in Fig. 3a-c for the months of October to December. The high resolution model distinctively captures the regions of surface warming similar to those shown by Overland and Wang (2010), i.e. areas where the sea ice retreated, over the Pacific sector in longitude range $\left(120^{\circ} \mathrm{E}-160^{\circ} \mathrm{W}\right)$ and in the Barents Sea and Siberian sectors in longitude range $\left(30^{\circ} \mathrm{E}-90^{\circ} \mathrm{E}\right)$ (see also Fig. 2). In Fig. 3, the red contour indicates the $90 \%$ significance level, determined from a Student $t$ test.

The corresponding 2007 anomalies in SLP are also shown in Fig. 3d-f. Over the Arctic Ocean in October and November, the low SLP anomaly is consistent with increased boundary layer thickness due to anomalous warming. Both $\mathrm{T}_{2 \mathrm{~m}}$ and SLP anomalies are robust in October and November, and appear consistently in every member of the 2007 ensemble.

The 2007 anomaly changes drastically over mid and high latitudes in December when the low level warming wanes and is replaced by deeper warm anomalies. At the surface, the warming becomes more pan-Arctic and spreads over continental Eurasia, north of $60^{\circ} \mathrm{N}$, and over the Bering Sea. The strongest SLP anomaly is over the North Pacific, and corresponds to a deeper than normal Aleutian Low. The 2007 upper-level (200 hPa) wind speed anomalies are presented on Fig. $3 \mathrm{~g}-\mathrm{i}$. Associated with the weakly westward-tilting vertical extension of the Aleutian Low, wind anomalies are strongest in December, when the Pacific jet has a pronounced eastward extension. An additional pair of SLP anomalies analogous to a positive NAO phase lies over the Atlantic sector. In addition, surface anticyclonic anomalies over North America and Eurasia provide anomalous advection of cold (warm) temperatures southward (northward) on their downstream (upstream) sides. This leads to longitudinal dipolar $\mathrm{T}_{2 \mathrm{~m}}$ anomalies over both continents, with cool anomalies on the eastern sides along the Pacific coast of Asia and over Northeastern North America. Warm anomalies resulting from anomalous southerly advection then appear at high latitudes over Northern Europe and Eurasia at $80^{\circ} \mathrm{N}$ (Fig. 2). Further hindsight can be gained from Hovmüller plots of daily 2007 anomalies in temperature averaged over the latitude band $75^{\circ} \mathrm{N}-85^{\circ} \mathrm{N}$, at the surface and at $850 \mathrm{hPa}$ (Fig. 4a, b). The near-stationary surface heating in longitudinal sectors where sea ice retreated has strongly decayed by the latter part of November, while eastward-travelling warm temperature anomalies are getting more prominent over the eastern hemisphere. The latter are also apparent at $850 \mathrm{hPa}$, 
Fig. 2 Vertical cross-sections of the 2007 monthly-mean temperature anomalies (see text for definition) along $80^{\circ} \mathrm{N}$ during October to December 2007

Fig. 3 October-to-December maps of monthly-mean 2007 anomalies in $\mathrm{T}_{2 \mathrm{~m}}(\mathbf{a}-\mathbf{c})$, sea level pressure $(\mathbf{d}-\mathbf{f})$ and $200 \mathrm{hPa}$ wind speed $(\mathbf{g}-\mathbf{i})$. The red contour indicates the $90 \%$ significance level, determined from a Student $t$ test. Note that maps $(\mathbf{d}-\mathbf{i})$ extend to $10^{\circ} \mathrm{N}$

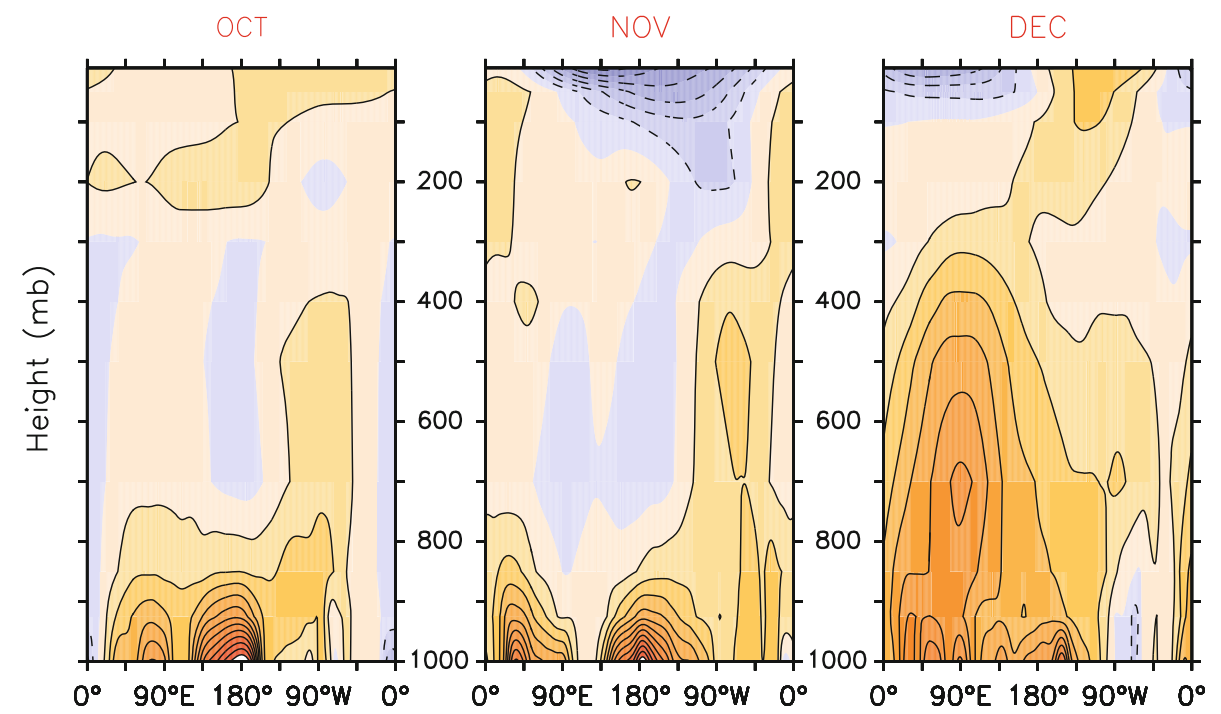

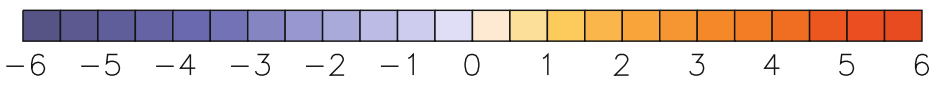

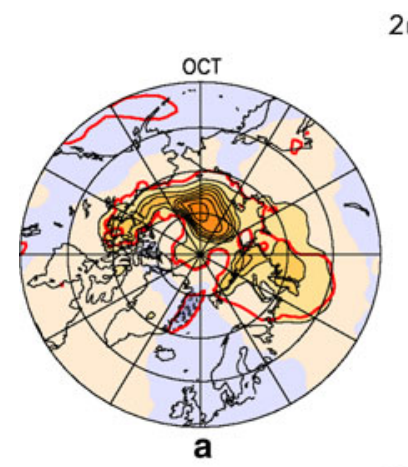

$2 \mathrm{~m}$ Air Temperature $\left({ }^{\circ} \mathrm{C}\right)$ Anomaly
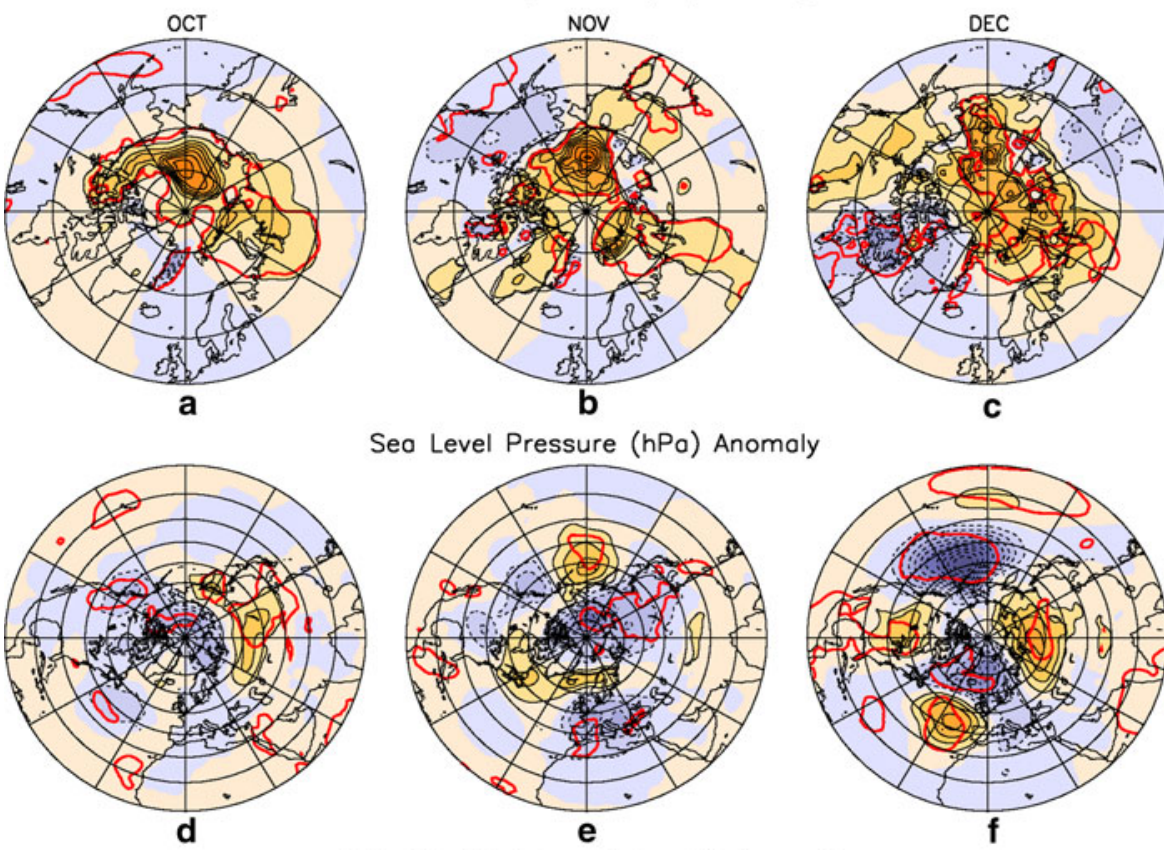

Seo Level Pressure (hPo) Anomaly
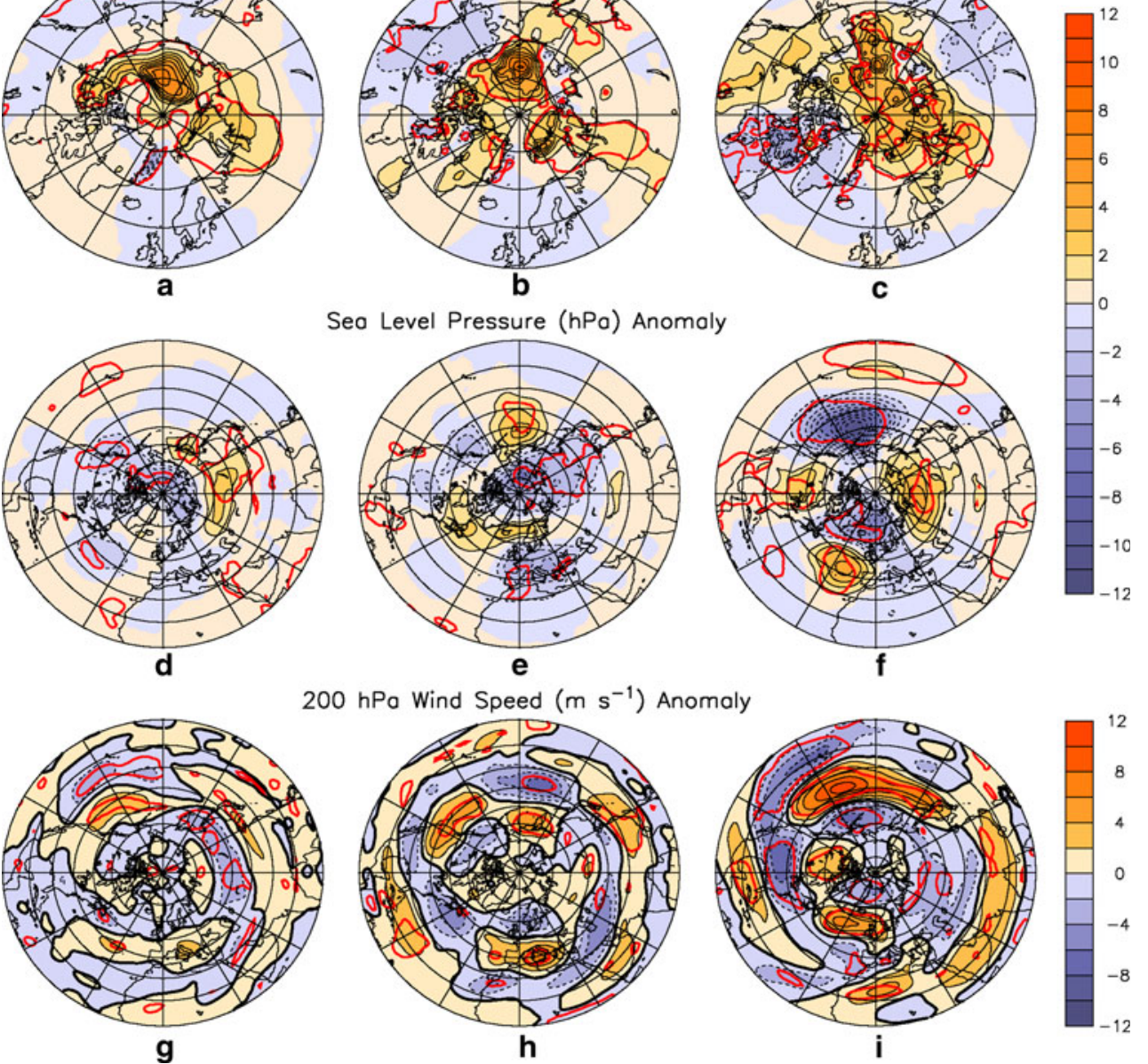
and leave a strong imprint in the December mean temperature cross-section in Fig. 2. These temperature anomalies in the eastern hemisphere are consistent with anticyclonic and southerly advection of warm air around the anomalous Eurasian High that is firmly established by December. These December 2007 temperature anomalies demonstrate the linkages between high and mid latitudes in the response to retreating Arctic sea ice. Over North America and Eurasia, the intensified Highs act to weaken and shift southwards the mid-latitude jet streams (Fig. 3i). Abrupt shifts in response to winter sea ice anomalies, indicative of changes in global circulation patterns, have been also reported in the simulations of Deser et al. (2004), Seierstad and Bader (2009) and Petouhkov and Semenov (2010).

\section{Modelled 2007 anomalies in eddy heat flux and snow depth}

In order to investigate the role of transient baroclinic eddies in the response to the sea ice retreat, we present an eulerian storm track diagnostic in the form of the meridional eddy heat flux at $850 \mathrm{hPa}$, high-passed for periods shorter than 7 days, using a Lanczos time filter (Duchon 1979). The 2007 monthly anomalies in the transient eddy heat flux, shown on Fig. 5, indicate an increase from October to December. Note that this anomaly increase does not reflect the seasonal March of baroclinic eddy activity, as the anomaly is the difference between the ensemble mean using the 2007 sea ice extent from the super-ensemble mean of hindcasts valid for the same period and using different sea ice conditions.

In December, there is a pronounced positive anomaly over the North Atlantic and Barents Sea $\left(30^{\circ} \mathrm{N}-60^{\circ} \mathrm{N}\right)$, where the anomalous flux extends to the northernmost latitudes. To the East, a negative flux anomaly prevails across Eurasia, especially on the eastern and western sides of the continent. Over the Pacific, the transient eddy activity is enhanced in the entrance and exit regions of the jet stream. Over North America, a reduction in eddy activity is less clear, merely confined to the central part of the continent. A reduction in transient eddy activity across continental Eurasia is qualitatively consistent with a high anomaly being established there in December,
Fig. 4 Hovmueller plot of daily temperature 2007 anomalies from October to December, averaged over the latitude band $\left(75^{\circ} \mathrm{N}-85^{\circ} \mathrm{N}\right)$ at the surface (a) and at $850 \mathrm{hPa}(\mathbf{b})$
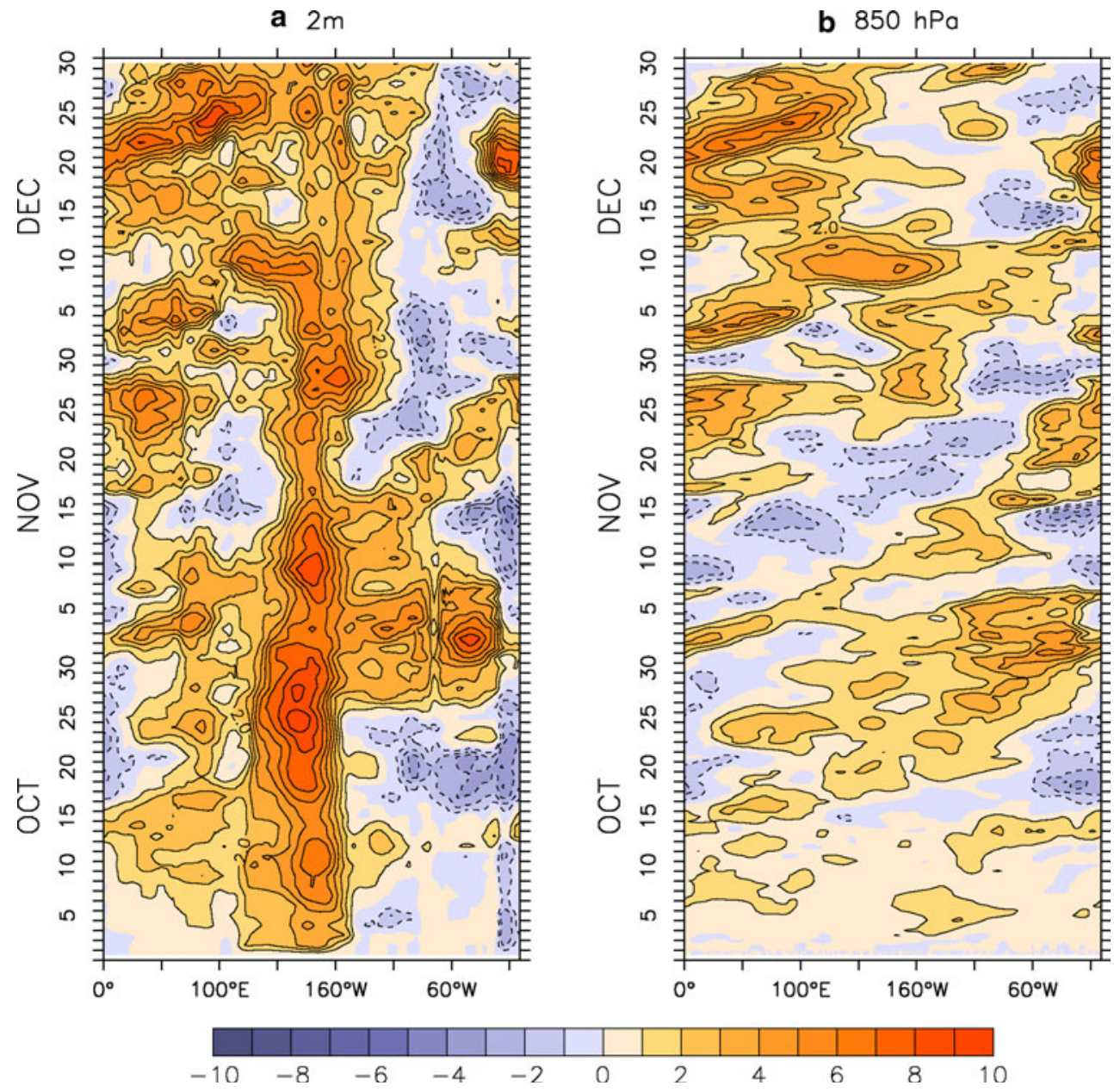


\section{0hPa 7-day High Pass Trans. Mer. Eddy Heat Flux Anomaly (K m s $\left.{ }^{-1}\right) \quad 2007$}

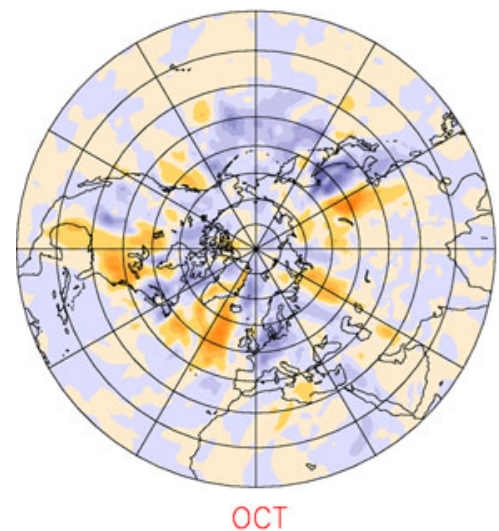

OCT

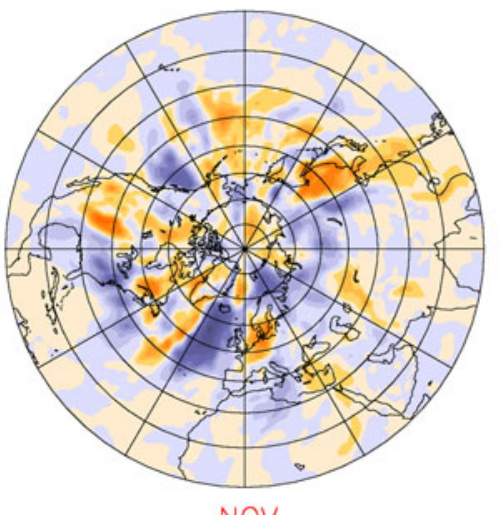

NOV

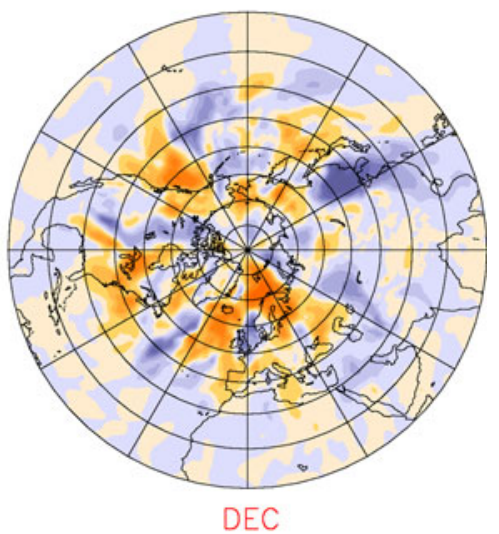

DEC

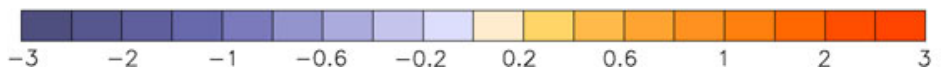

Fig. 5 October-to-December maps of monthly-mean 2007 anomalies in transient meridional eddy heat flux at $850 \mathrm{hPa}$ (in $\mathrm{K} \mathrm{m} \mathrm{s}^{-1}$ )

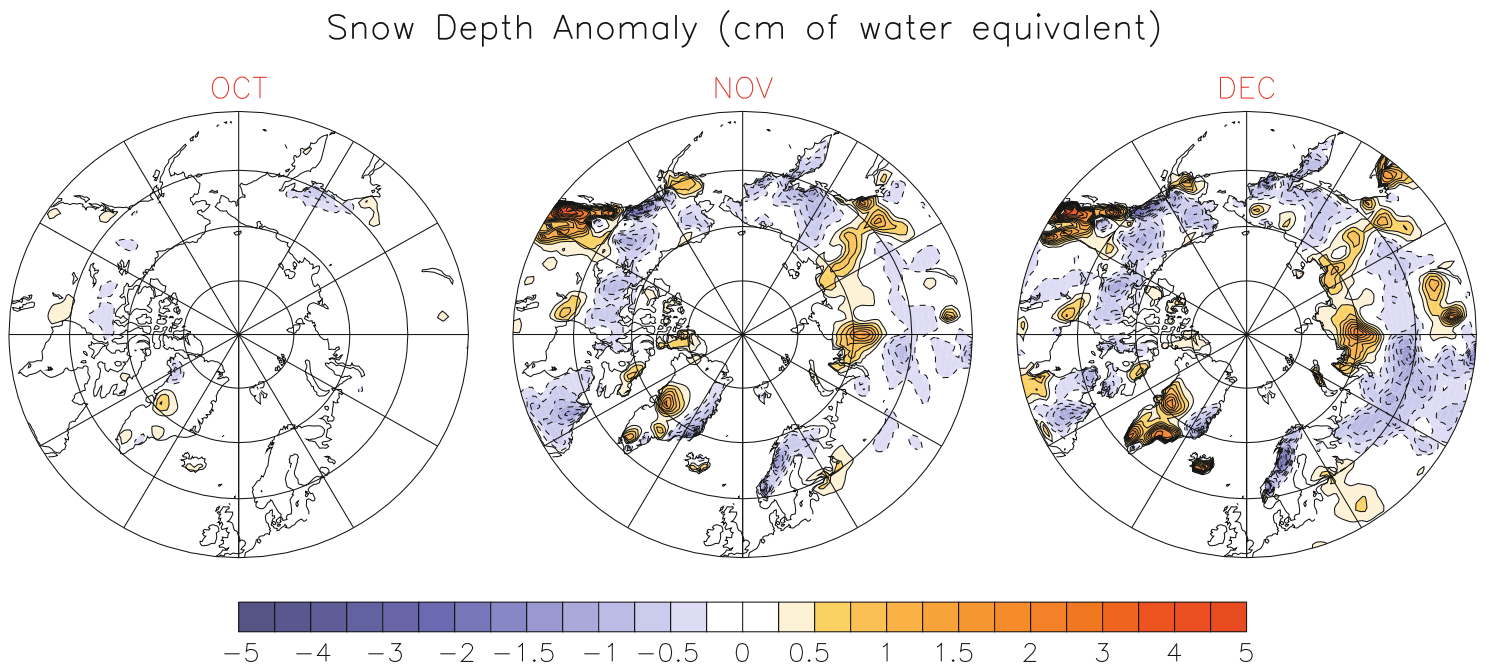

Fig. 6 October-to-December maps of monthly-mean 2007 anomalies in snow depth (in $\mathrm{cm}$ of snow water equivalent)

accompanied by the southward displacement and weakening of the jet stream across the continent (Fig. 3f, i), while increase over the oceanic sectors are also at least qualitatively consistent with intensification of the jet stream.

The above results indicate that transient eddies might play an important role in the atmospheric response. However, while we see changes both in the model jet structure and storm tracks, general circulation model simulations are notoriously difficult to diagnose in a causal way, because it is not possible to disentangle which of the transient eddies or the mean flow changes occurred first.

Anomalies are also found in snow depth in November, largely persisting into December 2007 (Fig. 6). Higher snow depths are found in November over the coastal regions of the Russian Arctic between $60^{\circ} \mathrm{E}$ and $140^{\circ} \mathrm{E}$, where they extend southwards, and lower snow depths are found eastwards of $140^{\circ} \mathrm{E}$. The negative anomalies over western Eurasia $\left(30^{\circ} \mathrm{E}-90^{\circ} \mathrm{E}\right)$ in December are consistent with the above-mentioned warm southerly advection.

\section{Potential predictability analysis of $T_{2 m}$ and SLP}

To estimate the impact of an external, boundary forcing in an ensemble prediction system, it is customary to calculate the potential predictability $(\Pi)$, based on an analysis of variance. The $\Pi$ analysis seeks to put an upper bound to the predictability related to the boundary forcing for the particular ensemble prediction system. $\Pi$ is defined as the ratio of external variance to the total variance, the latter is the sum of the external and internal variances. The external variance characterizes the response to the boundary 
forcing, in our case sea ice extent. It represents the variability of the 6 hindcast ensemble means, each one corresponding to sea ice extent from a given year. The internal variance represents the variability within the superensemble of 30 hindcasts. High values of $\Pi$, close to one, indicate regions where the sea-ice forcing exerts a dominant influence. Monthly-mean $\Pi$ for $T_{2 m}$ is shown in Fig. $7 \mathrm{a}-\mathrm{c}$ in the October to December period. In October and November, sea ice influences strongly the temperatures over the Arctic Ocean, with $\Pi$ close to 1 . In December, there is, in addition, a clear enhancement in $\Pi$ (up to 0.4) along the Pacific coast of Asia from Japan to China and Southeast Asia. It is in fact preceded by a weaker and more localized enhancement to the Northeast of that region in November. The influence of the sea ice retreat on $\mathrm{T}_{2 \mathrm{~m}}$ over the Pacific coast of Asia is further demonstrated in Fig. 8. Temperatures for the 2007 ensemble members, averaged over a box covering this area $\left(100^{\circ} \mathrm{E}-140^{\circ} \mathrm{E} ; 20^{\circ} \mathrm{N}-40^{\circ} \mathrm{N}\right)$,

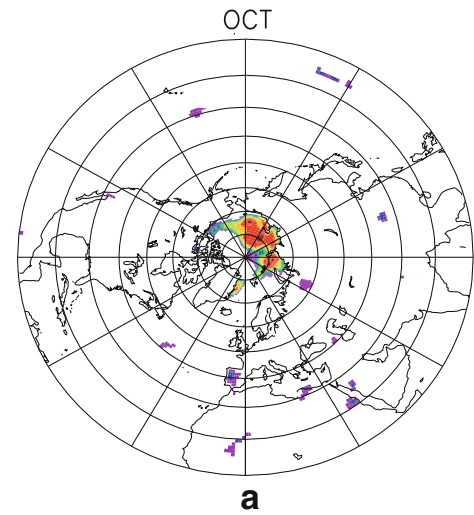

$2 \mathrm{~m}$ Air Temperature
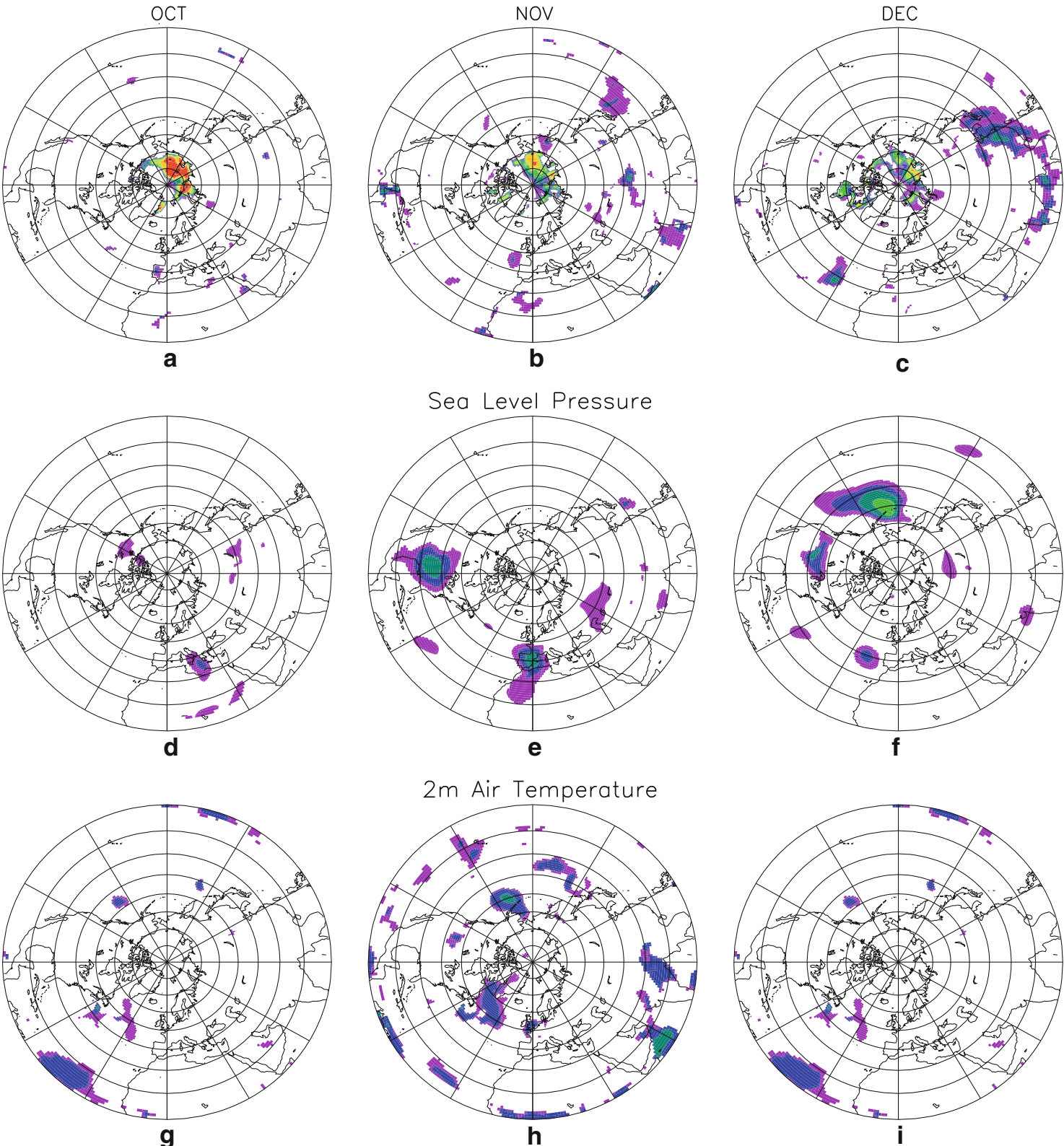

0.2

0.4

0.6

0.8

Fig. 7 Monthly-mean potential predictability of $\mathrm{T}_{2 \mathrm{~m}}(\mathbf{a}-\mathbf{c})$ and SLP $(\mathbf{d}-\mathbf{f})$, based on treating sea ice as external forcing, and of $\mathrm{T}_{2 \mathrm{~m}}$ based on treating SST as external forcing $(\mathbf{g}-\mathbf{i})$. Values are shown only where statistical significance exceeds $90 \%$ according to an $F$-test 
are consistently cooler by $1-2^{\circ}$ and show less member-tomember spread than the other ensembles. These cooler temperatures are consistent with anomalous southward advection of polar air by the intensified Eurasian High and Aleutian Low. While $\Pi$ is high in areas adjacent to the Arctic Ocean, incl. for example the Hudson Bay, the enhancement in $\Pi$ along the Pacific coast of Asia is the only remote (meaning outside of the Arctic Ocean) surface temperature response to sea ice in the October to December period.

We also calculated the $\Pi$ for the SLP field (Fig. 7d-f). Enhanced values around the Aleutian Low in December indicate that this sector is under influence of the sea ice extent. Finally, we also consider the $\Pi$ associated with SSTs by inverting the role of SSTs and sea ice forcings. Because the 5-member ensembles were generated by perturbing SSTs, $\Pi$ associated with SSTs can be estimated by considering that a given member being part of a 6-member experiment with fixed SSTs and generated by perturbed sea ice conditions. That is, the external variance was rather calculated for ensemble means of the six members with the same SST initial conditions but with various sea ice extents, as opposed to the same sea ice extent and varying SST initial conditions, as previously.

These new $\Pi$ maps (Fig. $7 \mathrm{~g}-\mathrm{i}$ ) for $\mathrm{T}_{2 \mathrm{~m}}$ do not show an enhancement along the Pacific coast of Asia, indicating that the latter is indeed linked to sea ice variability, and not to SSTs.

We further note that, over the fringes of continental Northern Eurasia (poleward of $70^{\circ} \mathrm{N}$ ), the model 2007 anomalies show a pronounced surface warming in December (Fig. 3c), in qualitative agreement with the

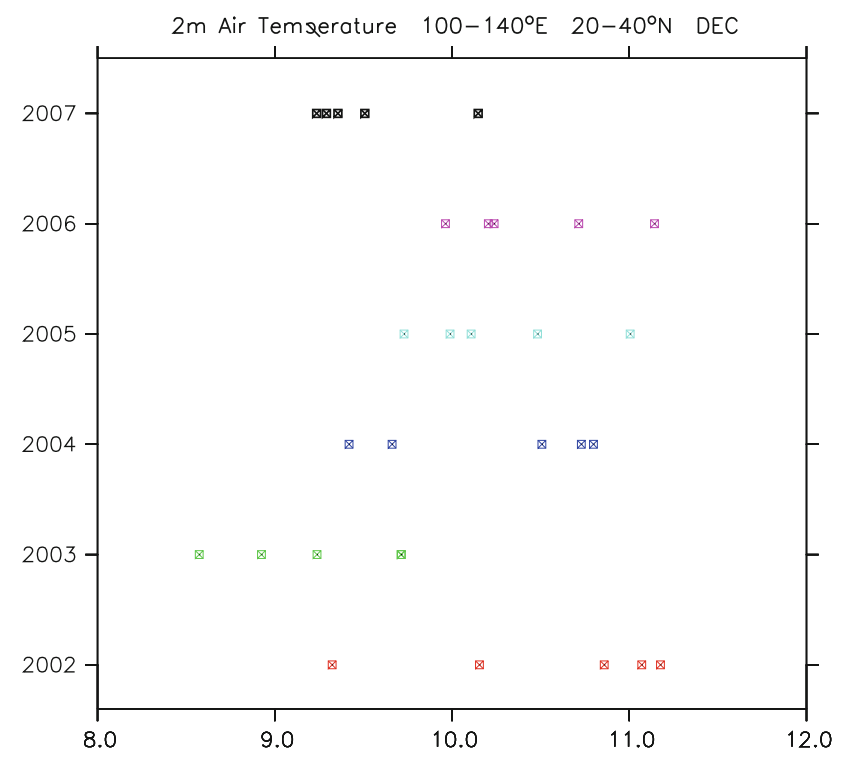

Fig. 8 Mean $\mathrm{T}_{2 \mathrm{~m}}$ over the Pacific Coast of Asia $\left(100^{\circ} \mathrm{E}-140^{\circ} \mathrm{E}\right.$; $20^{\circ} \mathrm{N}-40^{\circ} \mathrm{N}$ ) for the super-ensemble of 30 hindcasts using the various sea ice extents (2002-2006) model study by Lawrence et al. (2008) on Arctic sea ice retreat impacts. However, $\Pi$ is not enhanced over that region due to a large internal variance in $\mathrm{T}_{2 \mathrm{~m}}$ over land. For the same reason, the east-west oriented dipole of $\mathrm{T}_{2 \mathrm{~m}}$ anomalies over North America, e.g. in the latitude band $60^{\circ} \mathrm{N}-70^{\circ} \mathrm{N}$, is not revealed in the $\Pi$ map. Rather, $\Pi$ is only enhanced over the oceans where internal variability is less. Finally, no significant patterns were found in the corresponding $\Pi$ maps for snow depth (not shown).

\section{Modelled 2007 anomalies in the stratosphere}

The 2007 anomalies extend vertically from the surface into the upper troposphere, and further up into the stratosphere. In particular, the large modulation of the Aleutian and Icelandic surface Lows seen culminating in December in Fig. $3 f-i$, generates a planetary wave 2 that efficiently penetrates to the 50-hPa level. The anomalously weak polar vortex in December, distorted by a wave 2 disturbance is readily seen in Fig. 9, which shows the monthly 2007 geopotential anomaly at $50 \mathrm{hPa}$. It is unlikely that the stratospheric anomaly could exert a surface influence already in November and December through its downward propagation, but it may well play a role later in the winter. A potential predictability map for geopotential height at $50 \mathrm{hPa}$ (Fig. 10) reveals that enhanced values are found aloft and slightly equatorward of the surface centre of the Aleutian Low, reflecting the stratospheric influence of the sea ice through the SLP in the Aleutian sector in December.

\section{Improvement of surface temperature prediction at high latitudes}

To demonstrate the closer agreement of high-latitude $T_{2 m}$ between the hindcasts and ERA-Interim re-analyses when the 2007 sea ice is used, we calculated the non-centered spatial anomaly correlation coefficient (ACC) over the polar region $\left(60^{\circ} \mathrm{N}-90^{\circ} \mathrm{N}\right)$. In these calculations, the anomalies are deviations from the ERA-Interim 1989-2009 climatological mean. The ACCs from the 2007 ensemble of hindcasts reach higher values than those of other ensemble members through October, and remain in the upper range through November (Fig. 11). This indicates a positive impact of realistic sea ice conditions over Arctic surface temperatures lasting at least one month. Further calculations (not shown) indicate that the improvement in the first month originates in the Pacific sector, where sea ice strongly retreated. Beyond 40 days, the ACCs in all hindcasts begin to rebound above 0.5 , indicating low-frequency variability originating in another factor than the sea ice. 


\section{0hPa Geopotential Height (m) Anomaly w.r.t Super Ens Mean 2007}
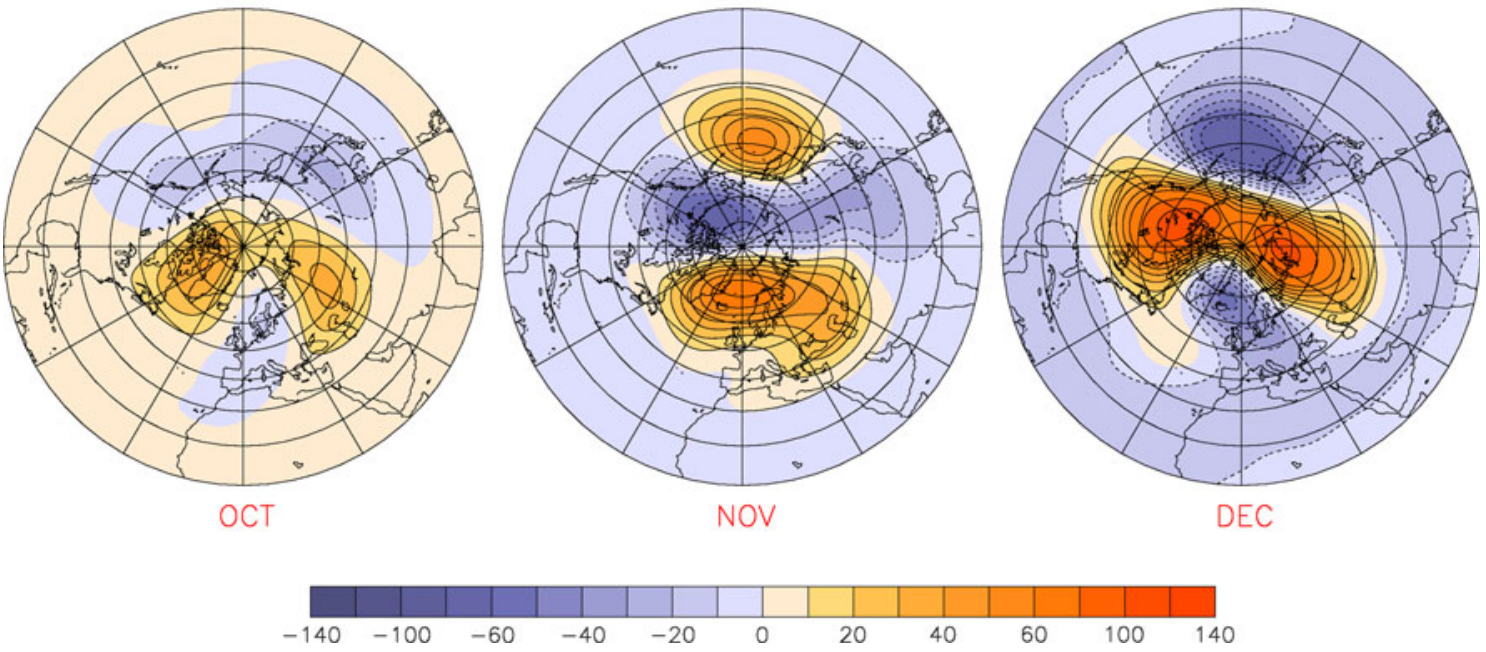

Fig. 9 October-to-December maps of monthly-mean 2007 anomalies in geopotential height at $50 \mathrm{hPa}$ (in m)

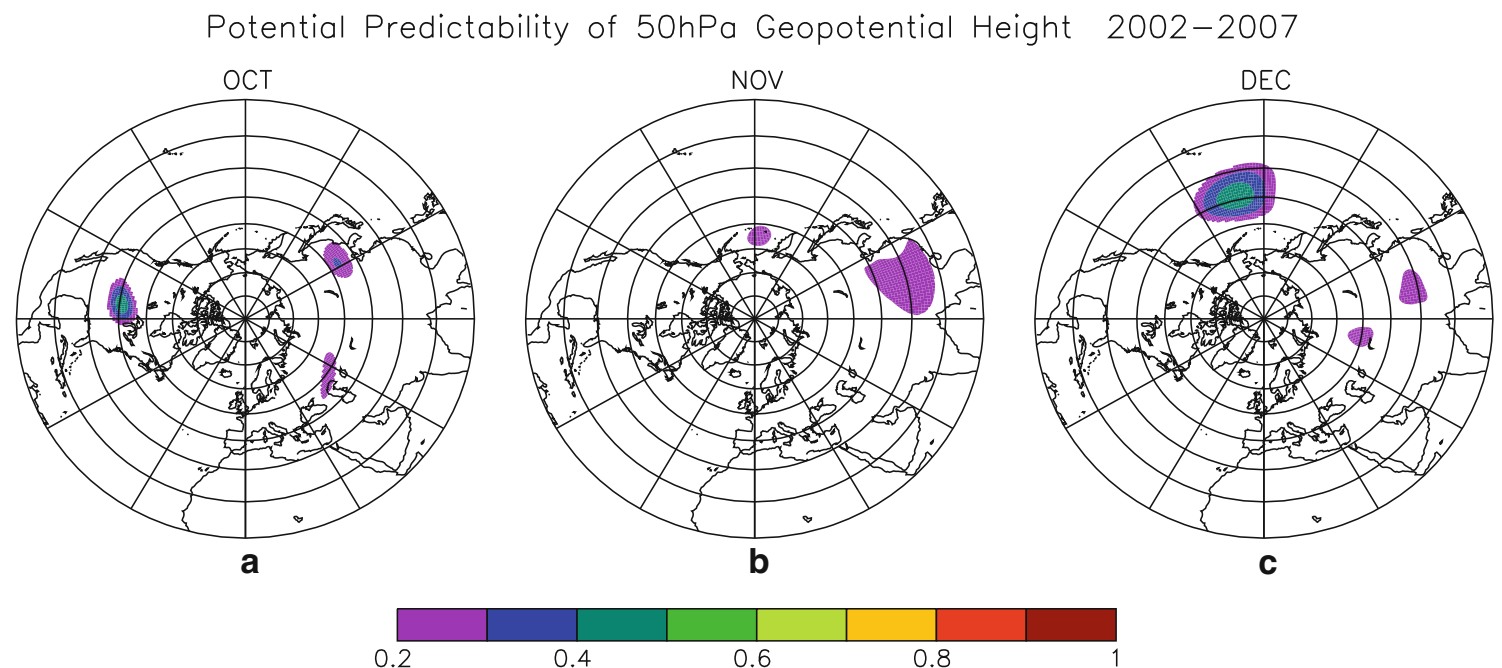

Fig. 10 Monthly-mean potential predictability of geopotential height at $50 \mathrm{hPa}(\mathbf{a}-\mathbf{b})$. Values are shown only where statistical significance exceeds $90 \%$ according to an $F$-test

Because we focused only on the year 2007, we cannot establish if there is a systematic, positive hindcast skill increment resulting from the sea ice extent being prescribed. To verify such a skill increment would require seasonal hindcasts spanning a decade or more.

\section{Summary and discussion}

Coupled, seasonal ensemble hindcasts with realistic oceanatmosphere-sea ice initialization and prescribed sea ice extent were performed to investigate the atmospheric response to the low sea ice extent in autumn and early winter 2007. Most of the earlier studies on the global response to Arctic sea ice anomalies were carried out with low or moderate resolution climate models, and not with high-resolution forecast models.

We now summarize our main findings. Potential predictability calculations indicate a strong influence of sea ice over the Arctic surface temperatures in autumn, but also along the Pacific coast of Asia in December. The latter appears as the region with the strongest sea ice sensitivity in $\mathrm{T}_{2 \mathrm{~m}}$, outside of the Arctic Ocean.

At high latitudes, an improved correlation of surface temperature hindcasts with meteorological re-analyses is found when realistic 2007 sea-ice conditions are prescribed.

Warm autumn anomalies are found in the hindcasts using the 2007 sea ice over the Pacific and Siberian sectors 
Anomaly Correlation Coefficient

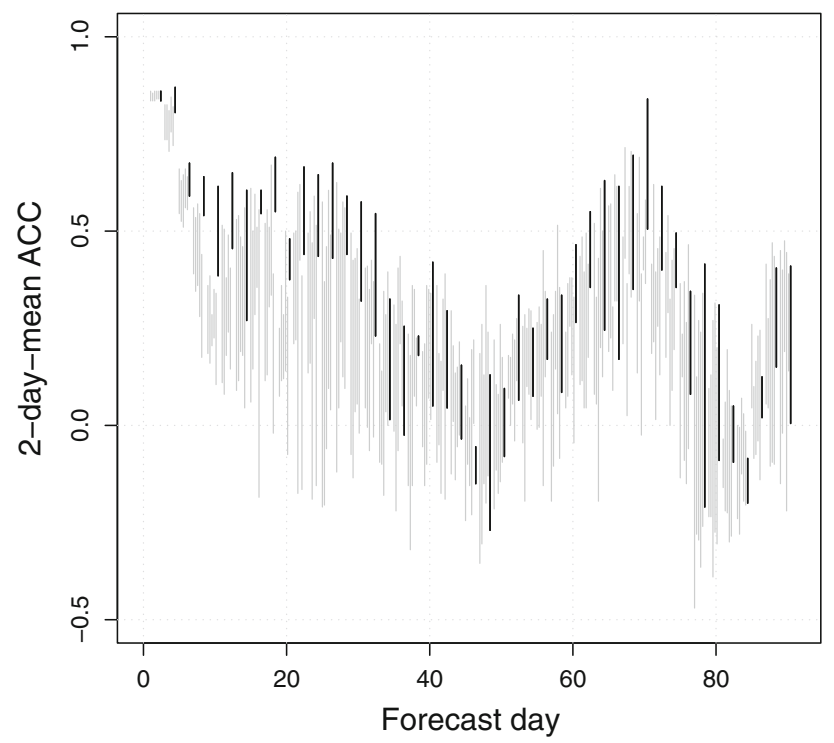

Fig. $11 \mathrm{~T}_{2 \mathrm{~m}}$ anomaly correlation coefficient (ACC) for all the hindcasts, as a function of forecast day (starting October 1, 2007), and calculated over high latitudes $\left(60^{\circ} \mathrm{N}-90^{\circ} \mathrm{N}\right)$. Two-day means are shown. Each black vertical bar is the envelope of the 5-member hindcasts using the 2007 sea ice, while the five grey vertical bars on its left are the envelopes of the 5-member hindcasts using the sea ice in preceding years (2002-2006)

of the Arctic, where sea ice had actually retreated. The warm anomalies, as high as $5-10^{\circ} \mathrm{C}$ at the surface, are in agreement with reanalysis-based studies (Serreze et al. 2009; Overland and Wang 2010; Screen and Simmonds 2010). In December, a regime change occurs indicative of strong feedbacks onto global circulation patterns. Hindcasted $\mathrm{T}_{2 \mathrm{~m}}$ anomalies are then weaker than in October and November but are extending through the troposphere and spreading over northern continental Eurasia. Prominent anomalies in SLP consist of a deeper Aleutian Low and an NAO positive phase. On the American and Eurasian continents, intensified surface Highs are associated with anomalous southward advection of cold polar air on their eastern sides, along the Pacific coast of Asia and Northeastern North America. They are also associated to anomalous northward advection of warm mid-latitude air on their western sides. Stronger, zonally-extended upperlevel jets are found over the oceanic sectors, while the Highs weaken and shift the jets southwards over the continents.

Modelled, warm low-level anomalies in October and November 2007 which we attribute to sea ice retreat over the Pacific and Siberian sectors of the Arctic are in agreement with observation-based studies cited above, which compared observed temperatures in 2007 with those of previous pentads or decades. It is also consistent with the recent model study by Kumar et al. (2010), who investigated the seasonality and vertical structure of the response to the observed sea ice extent of 2007 in AGCMs. Their study did not extend beyond November.

The improved correlation of high-latitude surface temperatures with meteorological re-analyses through October and early November 2007 is also in agreement with Strey et al. (2010), who applied to the Arctic a high-resolution, non-hydrostatic, mesoscale model with prescribed SST, sea ice and lateral forcing.

In December, the model deeper Aleutian Low is in qualitative agreement with the findings by Honda et al. (2009), based on regressions of observed NCEP SLP against Siberian sea ice extent. A clear parallel with these findings is however difficult to establish due to differences in the regional characteristics of the sea-ice forcing. In 2007, the atmospheric forcing was particularly strong in the Pacific sector of the Arctic, while the idealized summer sea-ice anomalies in Honda et al. (2009) were prescribed over the Siberian sector. Petouhkov and Semenov (2010) found a strong non-linearity in the indirect response to winter sea ice anomalies, with alternating positive or negative phases of a NAO-like pattern depending on the percent-wise intensity of the decrease, full reduction leading to a NAO-like positive phase. Enhanced surface Highs over Northern Eurasia in autumns following summers with low sea ice extents were also found in NCEP data (Overland et al. 2008). The observational study of Francis et al. (2009) found reduced baroclinicity and jet strengths from October to March. While we indeed find in December a weakening and southward shift of the jets over the continents of America and Asia, we rather find a strengthening over oceanic sectors. Honda et al. (2009) also indicated a reduction in the storm track in Central Eurasia in connection with a southward shifted jet stream. Inoue et al. (personal communication 2011) also found that winter Arctic cyclones tend to propagate along more poleward than eastward trajectories over the North Atlantic and Barents Sea in years with low sea ice. Jaiser et al. (2011) also found an earlier onset of baroclinicity north of $75^{\circ} \mathrm{N}$, and an increase in transient eddy heat flux across the whole Arctic troposphere in winter. Clearly, more detailed studies of synoptic processes during periods of Arctic sea ice retreat are desirable.

High snow depth anomalies over parts of Eastern Eurasia are found in our hindcasts in November and December 2007. Extended snow cover over Eastern Eurasia in autumn has been found to modulate the circulation over the North Pacific, and also the North Atlantic in late winter from its influence on the vertical and horizontal propagation of planetary waves in the upper troposphere and stratosphere (Cohen et al. 2007; Orsolini and Kvamstø 2009). The hints of autumn Eurasian snow cover anomalies linked to Arctic sea ice retreat in our hindcasts make a compelling case to investigate in more detail the Arctic moisture budget. 
Our model study along with the recently published one by Kumar et al. (2010) highlights the role of Arctic sea ice in influencing high latitude climate in late autumn and early winter, and in particular the impact of the sea ice retreat over autumn surface temperatures. Our model and potential predictability analysis goes beyond the empirical estimation of the sea ice contribution to the observed 2007 anomalies, by attributing temperature and circulation changes to sea ice extent variability.

A key issue to be addressed in future studies bears upon the likelihood of cold Eurasian winters in response to sea ice retreat (Honda et al. 2009; Overland and Wang 2010; Petouhkov and Semenov 2010). To investigate the late winter response, it would also be desirable to run a large ensemble of hindcasts with this model.

In addition to its climate relevance, the identification of a robust sea ice response may contribute to improvement of monthly to seasonal predictability with important societal benefits.

Acknowledgments This research was supported by the Norwegian Research Council, through the project \#178570 "Seasonal Predictability over the Arctic Region-exploring the role of boundary conditions". We acknowledge the European Centre for Medium-Range Weather Forecasts (ECMWF) for a special project computing support, M. Balmaseda for help with the model, and Drs. J. Inoue and I. Seierstad for helpful comments.

Open Access This article is distributed under the terms of the Creative Commons Attribution Noncommercial License which permits any noncommercial use, distribution, and reproduction in any medium, provided the original author(s) and source are credited.

\section{References}

Alexander MA, Bhatt US, Walsh JE, Timlin MS, Miller JS, Scott JD (2004) The atmospheric response to realistic Arctic sea ice anomalies in an AGCM during winter. J Clim 17:890-905

Balmaseda M, Vidard A, Anderson DLT (2008) The ECMWF ocean analysis system: ORA-S3. Mon Wea Rev 136(8):3018-3034

Balmaseda $M$ et al (2010) Impact of 2007 and 2008 Arctic ice anomalies on the atmospheric circulation: implications for longrange predictions. Q J R Meteorol Soc 136:1655-1664

Benestad R, Senan R, Balmaseda M, Ferranti L, Orsolini YJ, Melsom A (2011) Sensitivity of $T_{2 m}$ to Arctic sea ice. Tellus Ser A 63(2):324-337. doi:10.1111/j.1600-0870.2010.00488.x

Bhatt US (2008) The atmospheric response to realistic reduced summer Arctic sea ice anomalies. In: DeWeaver ET, Bitz CM, Tremblay L-B (eds) Arctic sea ice decline: observations, projections, mechanisms, and implications. Geophys Monogr Ser 180:91-100. AGU, Washington DC

Cohen J, Barlow M, Kushner PJ, Saito K (2007) StratosphereTroposphere coupling and link with Eurasian Land-Surface variability. J Clim 20:5335-5343

Deser C et al (2004) The effects of North Atlantic SST and sea ice anomalies on the winter circulation in CCM3. Part II: Direct and indirect components of the response. J Clim 17:877-889
Deser C, Thomas R, Alexander M, Lawrence D (2010) The seasonal atmospheric response to projected Arctic sea ice loss in the late twenty-first century. J Clim 23:333-351

Duchon CE (1979) Lanczos filtering in one and two dimensions. J Appl Meteor 18:1016-1022

Francis JA, Chan W, Leathers DJ, Miller JR, Veron DE (2009) Winter Northern Hemisphere weather patterns remember summer Arctic sea ice extent. Geophys Res Lett 36:L07503. doi:10.1029/2009 GL037274

Honda M, Inoue J, Yamane S (2009) Influence of low Arctic sea ice minima on anomalously cold Eurasian winters. Geophys Res Lett 36:L08707. doi:10.1029/2008GL037079

Inoue J, Kikuchi T (2007) Outflow of summertime Arctic sea ice observed by ice drifting buoys and its linkage with ice reduction and atmospheric circulation patterns. J Meteorol Soc Jpn $85: 881-887$

Jaiser R, Dethloff K, Handorf D, Rinke A, and Cohen J (2011) Planetary- and baroclinic-scale feedbacks between atmospheric and sea ice cover changes in the Arctic. Tellus A (accepted)

Johannessen OM et al (2004) Arctic climate change-observed and modeled temperature and sea ice. Tellus 56(A):328-341

Kumar A et al (2010) Contribution of sea ice loss to Arctic amplification. Geophys Res Lett 37:L21701. doi:10.1029/2010 GL045022

Lawrence DM, Slater AG, Thomas RA, Holland MA, Deser C (2008) Accelerated Arctic land warming and permafrost degradation during rapid sea ice loss. Geophys Res Lett 35:L11506. doi: 10.1029/2008GL033985

Ogi M, Yamazaki K (2010) Trends in the summer northern annular mode and Arctic sea ice. SOLA 6:041-044. doi:10.2151/sola. 2010-011

Ogi M, Yamazaki K, Wallace JM (2010) Influence of winter and summer surface wind anomalies on summer Arctic sea ice extent. Geophys Res Lett 37:L07701. doi:10.1029/2009GL0 42356

Orsolini YJ, Kvamstø N (2009) The role of the Eurasian snow cover upon the wintertime circulation: decadal simulations forced with satellite observations. J Geophys Res 114:D19108. doi:10.1029/ 2009JD012253

Overland JE, Wang M (2010) Large-scale atmospheric circulation changes are associated with the recent loss of Arctic sea ice. Tellus Ser A 62:1-9. doi:10.1111/j.1600-0870.2009.00421.x

Overland JE, Wang M, Salo S (2008) The recent Arctic warm period. Tellus Ser A 60:589-597. doi:10.1111/j.1600-0870.2008. 00327.x

Petouhkov V, Semenov VA (2010) A link between reduced BarentsKara sea ice and cold winter extremes over northern continents. J Geophys Res 115:D21111. doi:10.1029/2009JD013568

Rinke A et al (2006) Influence of sea ice on the atmosphere: a study with an Arctic atmospheric regional climate model. J Geophys Res 111:D16103. doi:10.1029/2005JD006957

Screen JA, Simmonds I (2010) The central role of diminishing sea ice in recent Arctic temperature amplification. Nature 464:1334 1337. doi: $10.1038 /$ nature 09051

Seierstad IA, Bader J (2009) Impact of a projected future Arctic Sea Ice reduction on extratropical storminess and the NAO. Clim Dyn 33:937-943. doi:10.1007/s00382-008-0463-x

Serreze MC, Holland MM, Stroeve J (2007) Perspectives on the Arctic's shrinking sea-ice cover. Science 315:1533-1536. doi: $10.1126 /$ science 1139426

Serreze MC et al (2009) The emergence of surface-based Arctic amplification. The Cryosphere 3:11-19

Steele M, Zhang JL, Ermold W (2010) Mechanisms of summertime upper Arctic Ocean warming and the effect on sea ice melt. J Geophys Res 115:C11004. doi:10.1029/2009JC005849 
Strey ST, Chapman WL, Walsh JE (2010) The 2007 Sea Ice minimum: impacts on the Northern Hemisphere Atmosphere in late autumn and early winter. J Geophys Res 115:D23103. doi: 10.1029/2009JD013294

Stroeve J et al (2007) Arctic sea ice decline: Faster than forecast. Geophys Res Lett 34:L09501. doi:10.1029/2007GL029703

Wang $\mathbf{J}$ et al (2009) Is the dipole Anomaly a major driver to record lows in Arctic summer sea ice extent? Geophys Res Lett 36:L05706. doi:10.1029/2008GL036706
Zhang X et al (2008a) Recent radical shifts of atmospheric circulations and rapid changes in Arctic climate system. Geophys Res Lett 35:L22701. doi:10.1029/2008GL035607

Zhang JL et al (2008b) What drove the dramatic retreat of arctic sea ice during summer 2007? Geophys Res Lett 35:L11505. doi: 10.1029/2008GL034005 